\title{
Perinatal outcome in pregnancies with nuchal cord: prospective cross-sectional study at tertiary care institute
}

\author{
Zaneta Dias*, Shailesh Kore \\ Department of Obstetrics and Gynaecology, Lokmanya Tilak Muncipal Medical College and Hospital, Mumbai,
} Maharashtra, India

Received: 16 April 2021

Accepted: 10 May 2021

*Correspondence:

Dr. Zaneta Dias,

E-mail: zanetaanndias@gmail.com

Copyright: ( $\odot$ the author(s), publisher and licensee Medip Academy. This is an open-access article distributed under the terms of the Creative Commons Attribution Non-Commercial License, which permits unrestricted non-commercial use, distribution, and reproduction in any medium, provided the original work is properly cited.

\begin{abstract}
Background: The umbilical cord around the neck of fetus at the time of birth is nuchal cord (NC). NC is blamed as a major cause of fetal distress and perinatal mortality. The present study was undertaken to found out the incidence of nuchal cord at delivery and its perinatal outcomes in babies born with NC.

Methods: Total 500 low risk women delivered either vaginally or abdominally after 34 completed weeks of gestation were included in the study. Cases with $\mathrm{NC}$ at the time of delivery were taken as study group and the cases which did not have NC served as control group. Various obstetric characteristics and perinatal outcome were studied.

Results: The frequency of NC found was $35.6 \%$ of all the deliveries. Women with age between 21-25 years showed the maximum presence of NC (11.4\%) and NC mostly seen between 38-40 weeks of gestation (24.8\%). Presence of NC had no statistical significance on the maternal age, parity, period of gestation, mode of delivery, presence of meconium stained amniotic fluid and fetal distress. Prolonged duration of labour was seen in the presence of NC. The presence of $\mathrm{NC}$ was directly proportional to the length of cord and umbilical cord coiling. Perinatal outcome of babies in terms of Apgar score and seen as NICU admissions rate were not statistically significant. Tight NC had a poor Apgar score needed more intensive care.

Conclusions: $\mathrm{NC}$ is a common finding at the time of delivery. The present study suggests that NC is not associated with significant perinatal outcome.
\end{abstract}

Keywords: Umbilical cord, Nuchal cord, Perinatal outcome, Fetal distress, Apgar score, NICU

\section{INTRODUCTION}

Nuchal cord is defined as umbilical cord being wrapped $360^{\circ}$ around fetal neck. ${ }^{1}$ It is one of the most common complications of umbilical cord. Pregnancy with nuchal cord is a high risk condition particularly during labour and delivery. Nuchal cords disrupt the normal flow of blood, gases and nutrients from the mother to the fetus and can cause severe injuries including birth asphyxia (hypoxic ischemic encephalopathy or HIE) and cerebral palsy. ${ }^{2}$ However NCs are seen in $13-30 \%$ of births with its prevalence increases with duration of pregnancy, from $5.8 \%$ at $20 \mathrm{wks}$ upto $29 \%$ at 42 weeks of gestation. The incidence of nuchal cord rose with advancing gestation from $12 \%$ at 24 to 26 weeks to $37 \%$ at term. ${ }^{3,4}$

Moreover, intra uterine life, which is sustained only by two small arteries and a tortuous vein coursing through a long flexible cord, hangs by a very delicate thread, the umbilical cord. ${ }^{5}$ It seems that this delicate thread to often is wrapped around the new-born's neck. If the umbilical cord becomes overstretched or compressed during labour, it usually leads to temporary fetal bradycardia, much like a hangman's noose. The nuchal cord is held responsible for problems that are encountered during delivery and is often cited as a major cause of fetal distress and perinatal mortality. ${ }^{6}$ 
Management practices have been controversial as some obstetricians prefer to deliver these babies by elective caesarean section and others by vaginal route. When detected antenatally by ultrasound, it has all the more biased obstetricians to deliver these babies by caesarean section. Furthermore, the fear of neonatal complications favours operative interventions. Hence, considering the above facts, the present study was conducted to establish the incidence of nuchal cord at delivery in the existing setup and its perinatal outcomes in babies born with nuchal cord.

\section{METHODS}

After obtaining Institutional Ethical Committee approval and written informed consent from all the patients, this prospective cross-sectional study was conducted in Department of Obstetrics and Gynaecology, at Tertiary Care Hospital during a period of two years from November 2017 to November 2019. Total 500 low risk women delivered either vaginally or abdominally after 34 completed weeks of gestation and those women willing to participate in the study were included. There were no interventions in the study. Women delivered before 34 completed weeks of gestation, women with obstetric high risk factor which is likely to alter perinatal outcome, pregnancies complicated by intrauterine fetal death (MSB), malpresentations and multiple gestations, gross congenital malformations of fetus, sonographically diagnosed nuchal cord and women undergoing elective CS for other obstetric indications were excluded from the study.

The management of the cases was done according to the unit protocol. Fetal heart rate (FHR) monitoring was done with intermittent auscultation with stethoscope every 30 minute in first stage of labour and every 10 minute in second stage of labour during propulsive phase of labour and after every contraction in expulsive phase of second stage of labour. All the deliveries were attended by a team from Obstetrics and Paediatric Department. The cases with nuchal cord at the time of delivery were taken as study group and the cases which did not have nuchal cord served as control group. A nuchal cord was considered to be loose when it could be easily uncoiled before delivery of the fetal trunk, (Type A). When it needed to be clamped and cut before delivery of the trunk, the nuchal cord was considered tight, (Type B). Any knot-true/false, hematoma, thickness of the cord etc was noted carefully. Total cord length was calculated by adding fetal portion length and placental portion length. Umbilical coiling pattern and number of complete coils noted. The management decisions like routine neonatal care, transfer to neonatal care unit, intensive care, etc was taken by neonatology doctor.

Various parameters studied were- maternal age, parity, period of gestation, and any antenatal high risk factors, duration of first and second stage of labour, presence of non-assuring fetal status in labour, meconium staining of the amniotic fluid at the time of labour, mode of delivery, indication for intervention, nuchal cord: type, length, number of coils, APGAR score at 1 and $5 \mathrm{~min}$ and perinatal outcome (HIE, birth weight, IUGR/SGA, admission to NICU, intrapartum still birth and neonatal death).

\section{Statistical analysis}

Statistical package for social sciences (SPSS) version 15.0 for windows was used for statistical analysis. Pearson Chi square test and Fischer's exact test were used for variables with nonparametric distribution. $\mathrm{P}$ values less than 0.05 with a $95 \%$ confidence interval were considered significant.

\section{RESULTS}

Out of 500 women who delivered, the presence of NC was seen in $178(35.6 \%)$ cases and the absence of NC was seen in $322(64.6 \%)$ cases. Women with age between 21-25 years showed the maximum presence of NC (11.4\%), also seen mostly between 38 - 40 weeks of gestation (24.8\%). The presence of meconium stained amniotic fluid was only $6.8 \%$ (34 cases) in women with the presence of NC while $9.6 \%$ (48 cases) in women who did not show the presence of $\mathrm{NC}(\mathrm{p}=0.3530)$. Prolonged duration of labour was seen in the presence of NC. There were no statistically significant differences in maternal demographic and obstetric features, except duration of labour as shown in Table 1 .

Table 1: Demographic and obstetric characteristics of patients.

\begin{tabular}{|c|c|c|c|c|}
\hline Characteristic & & Nuchal cord present & Nuchal cord absent & P value \\
\hline \multirow{5}{*}{ Age in years } & $\leq 20$ & $48(9.6 \%)$ & $54(10.8 \%)$ & \multirow{5}{*}{$>0.05$} \\
\hline & $21-25$ & $58(11.4 \%)$ & $108(21.6 \%)$ & \\
\hline & $26-30$ & $40(8 \%)$ & $106(21.2 \%)$ & \\
\hline & $31-35$ & $26(5.4 \%)$ & $48(9.6 \%)$ & \\
\hline & $36-40$ & $6(1.2 \%)$ & $6(1.2 \%)$ & \\
\hline \multirow{3}{*}{ Parity } & Primigravida & $84(16.8 \%)$ & $140(28 \%)$ & \multirow{2}{*}{$>0.05$} \\
\hline & Multigravida & $94(18.8 \%)$ & $182(36.4 \%)$ & \\
\hline & 35-37 weeks & $42(8.4 \%)$ & $92(18.4 \%)$ & $>0.05$ \\
\hline
\end{tabular}

Continued. 


\begin{tabular}{|c|c|c|c|c|}
\hline \multicolumn{2}{|c|}{ Characteristics } & Nuchal cord present & Nuchal cord absent & P value \\
\hline \multirow{2}{*}{$\begin{array}{l}\text { Gestational } \\
\text { age }\end{array}$} & $38-40$ weeks & $124(24.8 \%)$ & $216(43.2 \%)$ & \multirow{4}{*}{0.1271} \\
\hline & 41-42 weeks & $12(2.4 \%)$ & $14(2.8 \%)$ & \\
\hline \multirow{3}{*}{$\begin{array}{l}\text { Fetal heart } \\
\text { rate }\end{array}$} & Bradycardia & $22(4.4 \%)$ & $36(7.2 \%)$ & \\
\hline & Normal & $132(26.4 \%)$ & $260(52 \%)$ & \\
\hline & Tachycardia & $24(4.8 \%)$ & $26(5.2 \%)$ & \\
\hline \multirow{2}{*}{$\begin{array}{l}\text { Duration of } \\
\text { labour }\end{array}$} & Normal & $124(24.8 \%)$ & $280(56 \%)$ & \multirow{2}{*}{0.000001295} \\
\hline & Prolonged & $54(10.8 \%)$ & $42(8.4 \%)$ & \\
\hline \multirow{3}{*}{$\begin{array}{l}\text { Mode of } \\
\text { Delivery }\end{array}$} & ID & $52(10.4 \%)$ & $30(6 \%)$ & \multirow{3}{*}{$>0.05$} \\
\hline & LSCS & $22(4.4 \%)$ & $76(15.2 \%)$ & \\
\hline & VD & $104(20.8 \%)$ & $216(43.2 \%)$ & \\
\hline
\end{tabular}

Table 2: Neonatal outcome in both the groups.

\begin{tabular}{|c|c|c|c|c|}
\hline \multicolumn{2}{|c|}{ Characteristics } & \multirow{2}{*}{$\begin{array}{l}\text { Nuchal cord present } \\
20(4 \%)\end{array}$} & \multirow{2}{*}{$\begin{array}{l}\text { Nuchal cord absent } \\
30(6 \%)\end{array}$} & \multirow{2}{*}{ P value } \\
\hline \multirow{4}{*}{$\begin{array}{l}\text { Weight of } \\
\text { baby }(\mathbf{K g})\end{array}$} & $<2.5$ & & & \\
\hline & 2.5 to 3 & $82(16.4 \%)$ & $62(32.4 \%)$ & \multirow{3}{*}{$>0.05$} \\
\hline & 3 to 3.5 & $50(10 \%)$ & $88(17.6 \%)$ & \\
\hline & 3.6 to 4 & $26(5.2 \%)$ & $42(8.4 \%)$ & \\
\hline \multirow{3}{*}{$\begin{array}{l}\text { Apgar score } \\
\text { at } 1 \text { minute }\end{array}$} & 0 to 3 & $13(2.6 \%)$ & $33(6.6 \%)$ & \multirow{3}{*}{0.4661} \\
\hline & 4 to 6 & $146(29.2 \%)$ & $252(50.4 \%)$ & \\
\hline & 7 to 10 & $22(4.4 \%)$ & $34(6.8 \%)$ & \\
\hline \multirow{3}{*}{$\begin{array}{l}\text { Apgar score } \\
\text { at } 5 \text { minutes }\end{array}$} & 0 to 3 & $0(0.0 \%)$ & $0(0.0 \%)$ & \multirow{3}{*}{0.3000} \\
\hline & 4 to 6 & $42(8.4 \%)$ & $76(15.2 \%)$ & \\
\hline & 7 to 10 & $126(25.2 \%)$ & $256(51.2 \%)$ & \\
\hline \multirow{3}{*}{$\begin{array}{l}\text { Perinatal } \\
\text { outcome }\end{array}$} & NICU & $12(2.4 \%)$ & $38(7.6 \%)$ & \multirow{3}{*}{0.1617} \\
\hline & TCU & $43(8.6 \%)$ & $66(13.2 \%)$ & \\
\hline & Nursery & $122(24.4 \%)$ & $219(43.8 \%)$ & \\
\hline \multirow{3}{*}{$\begin{array}{l}\text { Number of } \\
\text { coils }\end{array}$} & 5 to 10 & $8(1.6 \%)$ & $90(18 \%)$ & \multirow{3}{*}{0.00000001} \\
\hline & 11 to 15 & $58(11.6 \%)$ & $212(42.4 \%)$ & \\
\hline & 16 to 20 & $112(22.4 \%)$ & $20(4 \%)$ & \\
\hline \multirow{5}{*}{$\begin{array}{l}\text { Length of } \\
\text { cord }\end{array}$} & $<40$ & $2(0.4 \%)$ & $18(3.6 \%)$ & \multirow{5}{*}{0.0000000001} \\
\hline & 41 to 50 & $10(2 \%)$ & $118(23.6 \%)$ & \\
\hline & 51 to 60 & $44(8.8 \%)$ & $122(24.4 \%)$ & \\
\hline & 61 to 70 & $90(18 \%)$ & $62(12.4 \%)$ & \\
\hline & $>70$ & $32(6.4 \%)$ & $2(0.4 \%)$ & \\
\hline
\end{tabular}

Table 3: Correlation of type/number of nuchal cord with obstetric characteristics.

\begin{tabular}{|c|c|c|c|c|c|c|c|c|c|}
\hline \multirow{2}{*}{\multicolumn{2}{|c|}{$\begin{array}{l}\text { Type of nuchal } \\
\text { cord / Number of } \\
\text { loop }\end{array}$}} & \multicolumn{3}{|l|}{ FHR } & \multicolumn{2}{|l|}{ MSAF } & \multicolumn{3}{|c|}{ Mode of delivery } \\
\hline & & Brady & $\mathbf{N}$ & Tachy & No & Yes & ID & LSCS & VD \\
\hline \multirow{2}{*}{$\begin{array}{l}\text { Type of } \\
\text { nuchal } \\
\text { cord }\end{array}$} & $\begin{array}{l}\text { Loose } \\
\text { (A) }\end{array}$ & $\begin{array}{l}11 \\
(7.8 \%)\end{array}$ & $\begin{array}{l}113 \\
(80.14 \%)\end{array}$ & $\begin{array}{l}17 \\
(12.06 \%)\end{array}$ & $\begin{array}{l}130 \\
(92.20 \%)\end{array}$ & $\begin{array}{l}11 \\
(7.80 \%)\end{array}$ & $\begin{array}{l}28 \\
(19.86 \%)\end{array}$ & $\begin{array}{l}12 \\
(8.51 \%)\end{array}$ & $\begin{array}{l}101 \\
(71.63 \%)\end{array}$ \\
\hline & $\begin{array}{l}\text { Tight } \\
\text { (B) }\end{array}$ & $\begin{array}{l}13 \\
(35.13 \%)\end{array}$ & $\begin{array}{l}17 \\
(45.95 \%)\end{array}$ & $\begin{array}{l}7 \\
(18.92 \%)\end{array}$ & $\begin{array}{l}32 \\
(86.48 \%)\end{array}$ & $\begin{array}{l}5 \\
(13.52 \%)\end{array}$ & $\begin{array}{l}24 \\
(64.86 \%)\end{array}$ & $\begin{array}{l}12 \\
(32.43 \%)\end{array}$ & $\begin{array}{l}1 \\
(2.71 \%)\end{array}$ \\
\hline \multirow{2}{*}{$\begin{array}{l}\text { Number } \\
\text { of loops }\end{array}$} & Single & $\begin{array}{l}12 \\
(10.16 \%)\end{array}$ & $\begin{array}{l}90 \\
(76.28 \%)\end{array}$ & $\begin{array}{l}16 \\
(13.56 \%)\end{array}$ & $\begin{array}{l}108 \\
(91.52 \%)\end{array}$ & $\begin{array}{l}10 \\
(8.48 \%)\end{array}$ & $\begin{array}{l}30 \\
(25.42 \%)\end{array}$ & $\begin{array}{l}12 \\
(10.16 \%)\end{array}$ & $\begin{array}{l}76 \\
(22.03 \%)\end{array}$ \\
\hline & Multiple & $\begin{array}{l}12 \\
(20 \%)\end{array}$ & $\begin{array}{l}40 \\
(66.66 \%)\end{array}$ & $\begin{array}{l}8 \\
(13.34 \%)\end{array}$ & $\begin{array}{l}52 \\
(86.66 \%)\end{array}$ & $\begin{array}{l}6 \\
(13.34 \%)\end{array}$ & $\begin{array}{l}22 \\
(36.66 \%)\end{array}$ & $\begin{array}{l}12 \\
(20.0 \%)\end{array}$ & $\begin{array}{l}26 \\
(43.37 \%)\end{array}$ \\
\hline
\end{tabular}

Perinatal outcome of the babies in terms of birth weight, APGAR Score and NICU admissions rate were not statistically significant, $(>0.05)$ but the presence of nuchal cord was directly proportional to the length of the cord and umbilical cord coiling as shown in table 2 . 
Table 4: Correlation of type/number of nuchal cord and neonatal parameters.

\begin{tabular}{|c|c|c|c|c|c|c|c|}
\hline \multirow{2}{*}{\multicolumn{2}{|c|}{$\begin{array}{l}\text { Type of nuchal cord } \\
\text { /Number of loop }\end{array}$}} & \multicolumn{2}{|c|}{ APGAR at 1} & \multicolumn{2}{|c|}{ APGAR at 5} & \multicolumn{2}{|c|}{ Perinatal outcome } \\
\hline & & $<7$ & $7-10$ & $<7$ & $7-10$ & TCU & NICU \\
\hline \multirow{2}{*}{$\begin{array}{l}\text { Type of nuchal } \\
\text { cord }\end{array}$} & Loose (A) & $\begin{array}{l}63 \\
(44.68 \%)\end{array}$ & $\begin{array}{l}78 \\
(55.32 \%)\end{array}$ & $\begin{array}{l}17 \\
(12.05 \%)\end{array}$ & $\begin{array}{l}124 \\
(87.95 \%)\end{array}$ & $\begin{array}{l}26 \\
(18.43 \%)\end{array}$ & $\begin{array}{l}115 \\
(81.57 \%)\end{array}$ \\
\hline & Tight (B) & $\begin{array}{l}33 \\
(89.18 \%)\end{array}$ & $4(10.82 \%)$ & $\begin{array}{l}15 \\
(40.54 \%)\end{array}$ & $\begin{array}{l}22 \\
(59.46 \%)\end{array}$ & $\begin{array}{l}26 \\
(70.27 \%)\end{array}$ & $\begin{array}{l}11 \\
(29.73 \%)\end{array}$ \\
\hline \multirow{2}{*}{$\begin{array}{l}\text { Number of } \\
\text { loops }\end{array}$} & Single & $\begin{array}{l}58 \\
(49.15 \%)\end{array}$ & $\begin{array}{l}60 \\
(50.85 \%)\end{array}$ & $\begin{array}{l}24 \\
(20.33 \%)\end{array}$ & $\begin{array}{l}94 \\
(79.67 \%)\end{array}$ & $\begin{array}{l}30 \\
(25.42 \%)\end{array}$ & $\begin{array}{l}88 \\
(74.58 \%)\end{array}$ \\
\hline & Multiple & $\begin{array}{l}38 \\
(63.33 \%)\end{array}$ & $\begin{array}{l}22 \\
(36.67 \%)\end{array}$ & $8(13.33 \%)$ & $\begin{array}{l}52 \\
(86.67 \%)\end{array}$ & $\begin{array}{l}22 \\
(36.66 \%)\end{array}$ & $\begin{array}{l}38 \\
(63.33 \%)\end{array}$ \\
\hline
\end{tabular}

The presence or absence of NC did not make any significant difference in the maternal outcome in this study. Maternal outcome was seen on the basis of women needing intensive care during delivery or post -delivery as unfavourable. Those women who were discharged on day 3 post normal vaginal deliveries, day 5 post instrumental and caesarean section was considered favourable, (Figure 1)

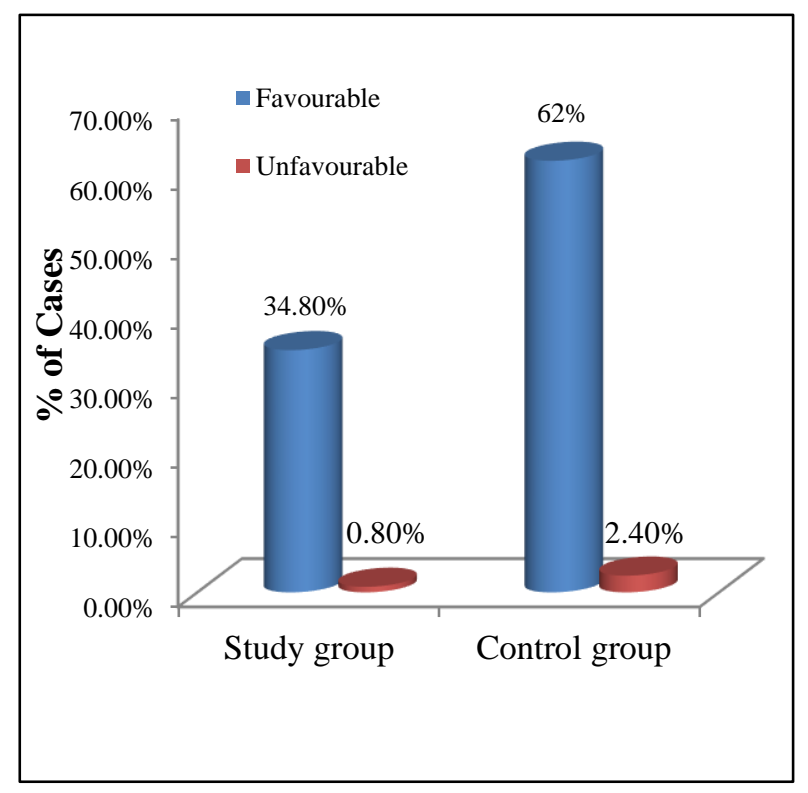

Figure 1: Maternal outcome.

Maximum number of cord had a single loop which was $23.6 \%$ (118 cases). The presence of double loop of cord around the neck was $8 \%$ (40 cases), triple loop 3.2\% (16 cases) and the quadruple loop was seen in only $0.8 \%$ (4 cases). Comparison between loose NC versus tight NC according to type of cord is depicted in figure 2.

The incidence of primary caesarean section, meconium staining, instrumental delivery- in tight cord group, i.e., it was found statistically significant $(\mathrm{p}<0.001)$. Also the incidence of instrumental delivery and caesarean section was more in women with multiple loop of cord around neck. (Table 3 )
The Apgar score of type A and B nuchal cords were compared and women having a tight nuchal cord had a poorer Apgar score at both one and 5 minutes most of them needing TCU/ NICU admissions. The perinatal outcome was poorer in NC type B as shown in table 4.

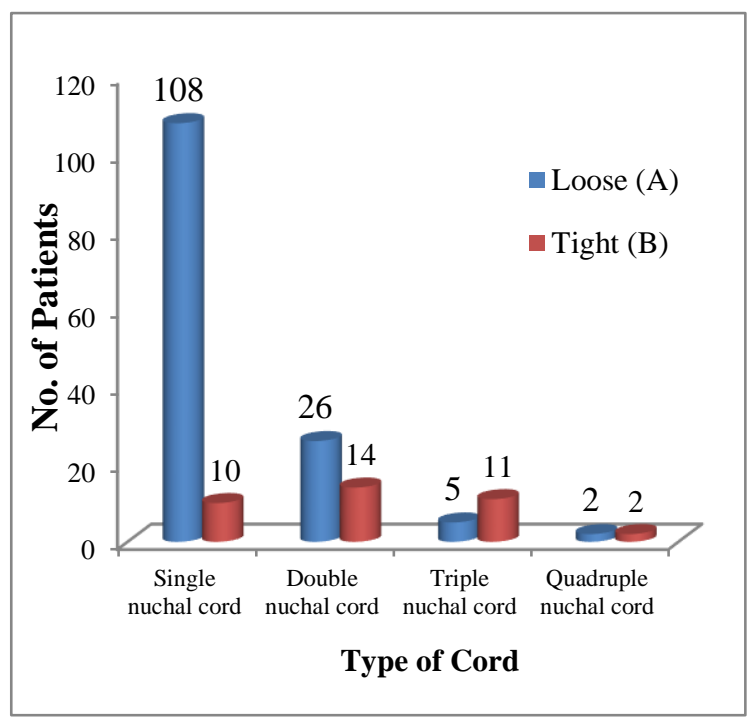

Figure 2: Comparison between loose NC (A) and tight $\mathrm{NC}$ (B)/ type of cord.

\section{DISCUSSION}

Perinatal outcome of nuchal cord is a controversial topic. Several studies have reported that nuchal cord is associated with adverse perinatal outcome. ${ }^{7-9}$ On the contrary, other studies could not demonstrate a negative effect of $\mathrm{NC}$ on the fetus; they found nuchal cord to be a normal part of intrapartum life that is seldom associated with any perinatal morbidity. ${ }^{9-11}$ Therefore, there is an on-going debate about the perinatal effects of nuchal cord. The incidence of nuchal cord in the present study was $35.6 \%$ which is comparable with the study done by Gupta et al $(32 \%) .{ }^{12}$ The reported incidence in Indian population varied from $5.3 \%$ to $10.9 \% .{ }^{13,14}$ But Miser et al and Shrestha observed quite higher $(24 \%)$ incidence as similar to present study. ${ }^{4,15}$ The incidence of single loop of cord was $23.6 \%$ while double was $8 \%$, triple being $3.2 \%$ and 
quadruple loops were $0.8 \%$ which is similar to findings in prior studies. $^{16,17}$

Age of the majority of patients $(33 \%)$ was within the range of 21-25 years with few elderly gravidas which is comparable with the study done by Begum et al. ${ }^{17}$ This age group showed the maximum presence of NC (11.4\%), as expected as this age group consists of most fertile women. The sample size catering to the study did not much of a difference between primigravida and multigravida. The presence of $\mathrm{NC}$ was seen mostly between 38-40 weeks of gestation $(24.8 \%)$. Sonographically diagnosed nuchal cord foetuses having gross congenital anomaly weren't included in the study. Difference in meconium stained liquor and fetal distress were statistically not significant. Prolonged duration of labour was seen in the presence of nuchal cord. These findings are correlated with the previous studies. ${ }^{16-18}$ Instrumental delivery rate was slightly more in study group than control group but statistically not significant. This finding is similar to study conducted by Sonawane et al, Mastrobattista et al and Peregrine et al. ${ }^{16,18,19}$

Perinatal outcome of the babies in terms of Apgar score at 1 and 5 minutes as well as NICU admissions rate were not statistically significant which is comparable with earlier studies. ${ }^{4,16,20}$ The presence of NC didn't show any adverse effect on the baby weight. The current study also helped with correlations with cord coiling and cord length. It showed that with increase in number of coils the percentage of NC were more, highest being 22.4 percent. The presence of NC increases with increase in length of the cord. Thus the presence of NC is directly proportional to the length of the cord and umbilical cord coiling. Nuchal cord had no significance in terms of maternal outcome. Multiple other studies were compared which dealt with perinatal outcome..$^{21-25}$

The current study also gave information on type A and type B nuchal cords. The incidence of instrumental delivery, caesarean sections were more with tight nuchal cords. The presence of fetal distress was significant in tight nuchal cords with a lower Apgar score which needed neonatal care unit admissions. Women undergoing elective caesarean sections weren't included in the study. Pregnancies complicated by intrauterine fetal death (MSB), malpresentations and multiple gestations and women with high risk obstetric factors which could alter perinatal outcome are also not included. The presence of multiple loop of cord around the neck also had a lower Apgar score compared to single loop of cord needing neonatal care. However, no adverse perinatal outcome was seen.

\section{CONCLUSION}

Nuchal cord is a common finding at the time of delivery. The results of present study indicate increased incidence with advancing gestational age need to be interpreted with caution because nuchal cord was not diagnosed antenatally, nor was it followed longitudinally. There was no increased risk for low Apgar scores, need for neonatal resuscitation, admission to the NICU, or any other neonatal morbidity. On the database forms, fetal heart rate was noted as normal, fetal bradycardia, fetal tachycardia or non-reassuring pattern. However, this did not result in any adverse neonatal outcome. Overall, we did not observe any increase in short-term maternal or neonatal adverse outcomes with nuchal cord.

Funding: No funding sources

Conflict of interest: None declared

Ethical approval: The study was approved by the Institutional Ethics Committee

\section{REFERENCES}

1. Crawford JS. Cord Round the Neck. Acta Paediatrica. 1962;51(5):594-603.

2. Peesay M. Nuchal cord and its implications. Matern Health Neonatol Perinatol. 2017;3:28.

3. Clapp JF, Stepanchak W, Hashimoto K, Ehrenberg H, Lopez B. The natural history of antenatal nuchal cords. Am J Obstet Gynecol. 2003;189(2):488-93.

4. Miser WF. Outcome of infants born with nuchal cords. J Fam Pract. 1992;34(4):441-5.

5. Miser WF. Outcome of infants born with nuchal cords. Obstet Gynecol Surv. 1992;47(11):767-9.

6. Singh G, Sidhu K. Nuchal Cord: A Retrospective Analysis. Med J Armed Forces India. 2008;64(3):23740.

7. Collins JH, Collins CL, Weekwerth SR, De Angelis L. Nuchal cords: timing of prenatal diagnosis and duration. Am J Obstet Gynecol. 1995; 17:768.

8. Jauniaux E, Ramsay B, Peellaerts C, Scholler Y. Perinatal features of pregnancies complicated by nuchal cord. Am J Perinatol. 1995;12(4):255-8.

9. Rhoades DA, Latza U, Mueller BA. Risk factors and outcomes associated with nuchal cord. A populationbased study. J Reproduc Med. 1999;44(1):39-45.

10. Clapp JF, Stepanchak W, Hashimoto K, Ehrenberg H, Lopez B. The natural history of antenatal nuchal cords. Am J Obstet Gynecol. 2003;189(2):488-93.

11. Sheiner E, Abramowicz JS, Levy A, Silberstein T, Mazor M, Hershkovitz R. Nuchal cord is not associated with adverse perinatal outcome. Arch Gynecol Obstet. 2005;274(2):81-3.

12. Gupta J, Sharma R and Gupta A. To study the effect of nuchal cord on perinatal outcome and mode of delivery in uncomplicated pregnancies. Int J Clinic Obstet Gynaecol. 2020;4(5):137-43.

13. Reed R, Barnes M, Allan J. Nuchal cords: Sharing the evidence with parents. Brit J Midwif. 2009;17(2):1069.

14. Chatterjee AK, Sengupta. Cord around the neck of the fetus. A study on 101 cases. J Obs Gyn India. 1989;39:660-4.

15. Shrestha NS, Singh N. Nuchal cord and perinatal outcome, Kathmandu University Medical Journal 2007;5(3):360-3. 
16. Sonawane PK, Bhadra DM. Comparative study of maternal and perinatal outcome in pregnancies with and without umbilical cord around foetal neck. Int $\mathbf{J}$ Reprod Contracept Obstet Gynecol. 2019;8:1096-9.

17. Begum AA, Sultana H, Hasan R, Ahmed M. A clinical study of fetal outcome in cases of nuchal cord. JAFMC Bangladesh. 2011;7(1):25-7.

18. Mastrobattista JM, Hollier LM, Yeomons ER, Ramin SM. Day MC, Sosa A et al 3rd. Effects of nuchal cord on birthweight and immediate neonatal outcomes. Am J Perinatol. 2005;22(2):83-5.

19. Peregrine E, O'Brien P, Jauniaux E. Ultrasound detection of nuchal cord prior to labour induction and the risk of caesarean section. Ultrasound Obstet Gynecol. 2005;25(2):160-4.

20. González-Quintero VH, Tolaymat L, Muller AC, Izquierdo L, O'Sullivan MJ, Martin D. Outcomes of pregnancies with sonographically detected nuchal cords remote from delivery. J Ultrasound Med. 2004;23(1):43-7.

21. Schreiber H, Daykan Y, Arbib N, Markovitch O, Berkovitz A, Biron-Shental T. Adverse pregnancy outcomes and multiple nuchal cord loops. Arch Gynecol Obstet. 2019;300(2):279-83.
22. Vasa R, Dimitrov R, Patel S. Nuchal cord at delivery and perinatal outcomes: Single-center retrospective study, with emphasis on fetal acid-base balance. Pediatr Neonatol. 2018;59(5):439-47.

23. Akkaya H, Büke B, Pekcan MK, Şahin K, Uysal G, Yeğin GF, et al. Nuchal cord: is it really the silent risk of pregnancy? J Matern Fetal Neonatal Med [Internet]. 2017;30(14):1730-3.

24. Walla T, Rothschild MA, Schmolling JC, Banaschak S. Umbilical cord entanglement's frequency and its impact on the newborn. Int J Legal Med [Internet]. 2018;132(3):747-52.

25. Ashok Phadol V, Sharad Naik A, Amit Naik S. Nuchal cord and perinatal outcome in a rural hospital: a case control study. J Evol Med Dent Sci. 2016;5(53):35315 .

Cite this article as: Dias Z, Kore S. Perinatal outcome in pregnancies with nuchal cord: prospective cross-sectional study at tertiary care institute. Int J Reprod Contracept Obstet Gynecol 2021;10:2368-73. 